\title{
Child Sexual Abuse in Pakistan: From Tears Shed to Lives Lost
}

\author{
Usman Shaukat Tarar ${ }^{1}$, Sharin Shajahan Naomi ${ }^{2 *}$ and Muhammad Aurangzeb Khan ${ }^{3}$
}

1. School of Integrated Social Sciences, The University of Lahore, Sargoda Campus, Pakistan.

2. Department of Gender Studies, Asian University for Women, Chittagong, Bangladesh.

3. Department of Social Work, Faculty of Social Sciences, Women University Swabi, Pakistan.

\begin{abstract}
Child Sexual abuse refers to sexual contact between a child and an adult or adolescent or use of a child for sexual purpose. In recent years many cases of child sexual abuse have been reported in Pakistan is an Islamic state where the lives and rights of every individual including child are protected by state through the Constitution, domestic legislations, and obligations under International Human Rights Conventions. The state is trying its utmost to remove the menace of child abuse, but still the issue is prevailing due to many social, psychological, and cultural reasons. Culprits have various reasons, from mental illness to illiteracy behind this practice. Parents are much busy in their day-to-day affairs that they have failed to give proper time and training to children so that they could address this issue in way that is more effective. This study examines reasons behind child sexual abuse in Pakistan along with the state's effort to overcome this evil. The findings shows that all social, religious, and legal obligations must be followed to eradicate this menace before this slogan will be chanted in every street "Jab sanbhal nae sktaytupaida q krtay o".
\end{abstract}

Keywords: Child Abuse, Sexual Abuse, Child Rights, Child Protection, Children Laws.

\section{Introduction}

Child abuse indicates sexual interaction with a child including penetration, touching, using child for the sexual stimulation of the perpetrator or an observer as well as humiliating and degrading the dignity of the child by any act related to sexual purpose. Child abuse generically is human originated acts of commission or omission and human created or tolerated conditions to inhibit or preclude the development of inherent potentials of children. Giovannoni (1971) defined abuse as acts of commission that result in harm, and neglect as acts of omission that have negative effects. Abuse is an exploitation of the rights of the parents to control, discipline, and punish their children while neglect represents the failure to perform parental duties including those of supervision, nurturance, and protection (Khan, Khan, \& Ali, 2017). It is further divided into four major categories i.e., physical abuse, physical neglect, emotional abuse and emotional neglect. Another definition of child abuse, which is indirectly or directly related to child sexual abuse is any parental/caretaker act or failure to act resulting in death, serious physical or emotional harm, sexual abuse or exploitation; or an act or failure to act which presents an imminent risk of serious harm to the child's physical or emotional health and development (National Clearinghouse on Child abuse and Neglect Information, 2006). Sexual abuse is often subsumed under physical abuse. However, it has its unique characteristics 
that differentiate it from other kinds of maltreatment, such as forceful sexual intercourse and inappropriate touching with a motive to meet sexual desire.

According to the report by a NGO 'SAHIL', more than 2000 child are sexually abused in Pakistan in a year including both female and male child (Imdad, 2019). Pakistan is land of pure people, where purity disappears when we see a series of child sexual abuse from the case of Kainat Somroo in 2007 to Zainab Ansari in 2018. Incidents like abduction, rape, and brutal killings of children in Pakistan are a matter of great concern for everyone in and outside the country. On one side, it is establishing a sense of insecurity and uncertainty in minds of the people, especially in the young generation, and on the other side the failure to stop this evil from rising in high rate putting question mark on the performance of state institutions before the citizens and international community. It is a time to ensure that every child may awake with smiling face all parents could sleep with satisfied minds. We cannot afford innocent children in the hands of monsters; we cannot afford to be victimised in either one way or the other (Khushhal, Zahid, \& Jan, 2017).

"Tears speak more loudly than words" when there is nothing to say. We are passing through such a critical phase of life as Pakistani where we feel ourselves just silent spectators. Parents are afraid, children are unsafe, moral corruption is at its peak and frustration is deteriorating humanism. All are equally responsible for these grievances from individuals to institutional level. We cannot overlook individual responsibilities. Because in those societies where individuals do not fulfil their duties such uncertainties become a usual practice (Bano, 2017). Pakistan is the Islamic Republic with strong commitment to international human rights laws, where laws do not allow anyone to violate human rights in any form. Then question is this why our children are not safe from sexual abuse and why culprits do not feel fear? Answers to these questions are quite simple though sorrowful. The state is doing maximum to avoid addressing this issue. However, role of the people is also inevitable to make Pakistan heaven for children.

Child sexual abuse is intentional exposure of a child towards a sexual activity, which is not acceptable or even known for a child. In this situation, a child is provoked, forced, or involuntarily asked for sexual activities by someone. This process includes various acts such as rape, inappropriate touching of a child's body and exposure to pornography. Pakistan is a state where everyone has a right to live in accordance with his/her fundamental rights. Constitutional rights of people ensure the security of every citizen including children with best possible facilities. Article, 25(3) of the Constitution of Pakistan grants special right for the protection of children due to their vulnerability. Pakistan has also ratified the International Convention on the rights of the child in 1990, which provides broader outlines for protection of child rights (Khan, Rehman, Muhammad, 2017).

The society needs to understand about child abuse and neglect in the historical, social, and political frameworks which are also discussed in a vaster arena by including various issues like, causes of the exploitation, maltreatment, and misuse of children throughout the globe; sexual exploitation of the children on a commercial basis; child abuse through the internet; and controversies with reference to the child deaths. Preventive measure for child abuse requires readings for the students along with practitioners of social work who are paying their services in the field of child protection (Brian Corby, 2006). It is not only the female children who are subject to abuse. Victimisation and socialisation of males and impacts of several types of sexual abuse of male children are also the discussion points of the day. Studies have shown that male children have specific and some more long-term effects of victimisation. New dimensions of 
male sexual victimisation have been discovered. The modern societies have been facing new concepts of the sexual abuse including social and sexual problems, which are shown by the males. We need a more explicit kind of model for formulation of treatment plan which should focus on systematic multi-remedial evaluation for adult males and male children (Frank, Morris, \& MacEachron, 1989).

Study of the child sexual abuse provides an insight about the dynamics, causes, and effects, options regarding the treatment and various preventive measures, which are available for both children as well as adults who are involved in the child sexual abuse. We need to give an emphasis along with guidance regarding counselling pathways for the victimised persons to start new, healthy, and more productive lives which may be available for the rehabilitation of personality traits of rehabilitates (Rowan, 2006; Khan, Ullah, \& Ali, 2018). SAHIL paid an attribute to this process to a tendency in the cultures of South Asia to detain girls indoors and stop their socialisation as a method to prevent from any incidence of the sexual abuse, which could make them more vulnerable to their incest (Cruel Numbers, 2019). On the other hand, boys are considered as not to be facing any such kind of threats and this understanding at the point keeps boys in a comparatively more vulnerable situation, especially in such cases when kids are sent to the shops to purchase various commodities for their daily use (Bano, 2018).

\section{Research Methodology}

This exploratory research has been conducted through mixed approach. The study is descriptive, theoretical, and qualitative. Data is collected for this study through primary and secondary sources. The primary sources included the newspapers and archives of official documents of the government, the legislatures, and the judiciary. Newspapers were consulted for analysing news items and public statement of government and public office holders. The topic includes recent case studies. Interviews were conducted with politicians, advocates of the superior courts, retired military personnel and those who either were involved in the processes or were witnesses to the problem under investigation. The theoretical and historical aspects of the study were dealt with through secondary resources, such as reference books, journal articles, newspaper articles, relevant theses, and reports. The secondary sources included both published and unpublished material on the subject. Analysis of statements, books, journals, magazines, gazetteers, newspapers, and government records was also made for the purpose.

\section{Discussions and Findings}

This finding of the current study appears to be consistent with researches indicating that abusive parents differ from matched control parents in ways they interact with their children (Starr, 1987; Wolfe, 1985) and hold negative emotional traits like hostility and rejection, detached and unresponsive parenting (Gelfand \& Teti, 1990). The discussion suggested that severely abused children perceived their parents, both fathers and mothers, more rejecting than other two abuse groups.

\subsection{Demographical Illustration of Child Abuse in Pakistan}

"Cruel Numbers" report by the SAHIL, shows that there is a $32 \%$ increase in child abuse cases in 2018 as compared to the previous year's numbers. From January 2018 till June of the same year total number of cases was 2322, which was 1764 in 2017 from January to June. In 2017, an average of nine cases of sexual abuse was reported per day, which moved up to 12 cases per 
day in 2018. According to a report submitted to the Senate Special Committee on the issue of increasing incident of child abuse, among all reported cases in Pakistan, 65\% cases were only from Punjab, 25\% cases were from Sindh, 3\% cases were reported from KPK, 3\% cases from Islamabad and $2 \%$ cases of child abuse were from Baluchistan. From total 2322 cases 1024 cases were relevant to the boys and 1298 girls were the victims (Bano, 2018).

\begin{tabular}{|l|c|c|}
\hline No. & Age period (Years) & Total Number of cases \\
\hline 1 & $1-5$ & 321 \\
\hline 2 & $6-10$ & 526 \\
\hline 3 & $11-15$ & 622 \\
\hline 4 & $16-18$ & 161 \\
\hline 5 & Age not cleared & 692 \\
\hline
\end{tabular}

Source:https://www.pakistantoday.com.pk/2018/08/30/almost-12-children-abused-in-pakistan-every-day-reportreveals/

\subsection{Factors behind the Sexual Abuse: A Social Narrative}

Among many issues, 'social isolation' is one of the major reasons, which leads a person towards the child sexual abuse either as a culprit or as a victim. A person who has a lack of bond with society usually remains unaware of social norms and values. No matter this isolation is because of disabilities or because of any other reason, it causes disastrous results for community. In Pakistan, people own their children with all their fundamental rights. However, in some cases, parents are too busy in their jobs or business that they cannot give proper time to their siblings. This parents-child gap removes check and balance from the activities of children. Ultimately, results are in shape of many social evils including sexual abuse. In a society, where people are always at dead end to cope with their necessities, issues in domestic affairs are not a very strange thing. Sometimes, parents move one-step further in their domestic issues that they forget impacts on children. Continuous 'pull down' situation creates rebellious attitude in those children, and they opt unfair routes to satisfy their needs. Dorothy Parker rightly speaks that "The best way to keep children at home is to make the home atmosphere pleasant and let the air out of the tires" (Sehrish, 2018).

Parents are always considered as the first institution of learning. If they play their positive role in overall nurture of their children, then a satisfied society is obvious. However, many parents support their children for their wrong deeds without knowing its impacts. So, this, relaxation makes them stronger and children do not feel hesitate to get indulge in malpractices (Gilbert, 1997). This problem is deeper in the marginalized and poor communities. "Society accepts the perfects." One who is misfit has no right to live in less developed societies. Same is the case with Pakistani society; a person cannot ensure basic needs with respect until he proves that he is capable of them. Socio-economic gap determines the social status of people, which determines that either a person is a privileged one or deprived one. For the deprived one, child abuse is something to be covered due to social stigma or compromised in exchange of money (Khan, Khan, \& Khan, 2017).

The children with learning disabilities are another most vulnerable groups to be given special protection. Learning disabilities means that one does not have the ability to understand. If a person is unable to understand the difference between right and wrong, then how to it will be possible for him/her to act or raise voice against any violation of rights. In Pakistan, it is common that society does not own those people who are disabled by any means. Rejection by 
the others wounds us psychologically. Hence, a rejected person in majority of the situations, if not hugged becomes more frustrated and silent in sharing the torture from sexual abuse.

\subsection{State's Efforts in Legal Paradigm: Achieved Milestones}

Pakistan was the sixth state to become a member of UNICEF. Pakistan is a party to UN Convention on the Rights of the Child, which actually is a treaty for human rights and focuses on social, political, cultural, civil, cultural, and health rights of children. Being signatory of this convention Pakistan is also working for the rights of children with assistance from UNICEF (Convention on Rights of Child, 1990). The Article 25 of Pakistan's constitution talks about the equality of citizens. This article explains that: a). All the citizens are equal before the law and have right to equal protection under umbrella of law. b) There will be no discrimination based on sex. c) Special provision should be made for the protection of children and women. Besides these provisions, the clause 3 of Article 25 focuses on the fact that the state must opt suitable measures to protect children against various malpractices because of their vulnerability (The Constitution of Islamic Republic of Pakistan).

National Commission on the Rights of child Act, 2015 was promulgated with its extension to whole Pakistan with following main functions:

- Examination of existing and proposed legislation related to child rights

- To make liaison with provincial commissioners and Organization with respect to child rights

- Examination and review of laws and policies related to child protection

- Inquiries into the violation of child rights and referral of the case to concerned authority or department

- Spread awareness and arrange dialogues on child rights

An act was also passed with the title Child Protection System Bill, 2014. This act has its jurisdiction within the capital territory of Islamabad. Under powers from this act, a commission was established with following agenda.

- The commission shall examine all policies, programs and other measures taken by the government for the implementation of UN Convention on Rights of Child.

- To make strategies and set targets for prevention, rehabilitation, protection, and reintegration of children at risk.

The Punjab Destitute and Neglected Children Act 2004, was promulgated on 22 June 2014. This act has its operational jurisdiction within the boundaries of Punjab province. This act works for following main reasons:

- To establish, recognise and protect child protection institutions

- To regulate the affairs of children protection institutions

- To punish the persons who take children in their illegal custody for any reason

The Sindh Child Protection Authority Act, 2011. Sindh Act No. XIV Of 2011 is also ensuring children rights with main purposes:

- To coordinate and monitor the child protection related issues at the provincial and district level

- Special protection measures will be ensured for children as their right, in time of need

- To ensure primary efforts to enhance and strengthen the existing services of different 
children welfare institutions

- To supervise in the light of minimum standards, the functions of all such institutions established by the government or private sector for the special protection measures of the children

The Khyber Pakhtunkhwa government introduced an act as "Khyber Pakhtunkhwa Child Protection and Welfare Act, 2010". This act states that:

- A person who will be involved in child sexual abuse will be imprisoned for 14 years which may not be less than 7 years

- Child trafficking within Pakistan is an offence which will be rewarded with life imprisonment

- To seduce a child in order to involve in any kind of sexual activity or try to exposes him to obscene and sexually explicit material, a film, document, video or a computer generated image or efforts for aforementioned action will have rigorous imprisonment of seven years or liable to fine of ten hundred thousand rupees or with both

- An offence of child pornography has a punishment of 3-7 years with a fine of 2 hundred thousand.

- Fraud or deceit on children by any means to engage in an activity, which is disastrous for emotional, physical, economic, mental and for child's social well-being, will be considered as an offence with three-year imprisonment and fine.

The Balochistan Child Protection Bill 2015, (Bill No.10 of 2015) having been passed by the Provincial Assembly of Baluchistan on $07^{\text {th }}$ November 2016 and is called as "The Baluchistan Child Protection Act, 2016. ACT NO. VII 0F 2016". It was promulgated to establish a Child Protection Commission within the social welfare, literacy and non-formal basic education, special education and Human Rights Department for providing vision, policy guidelines, and appropriate strategies for child protection, analysis of trends and adjusting policies and measures for the protection of children. Its main aim is the protection of children in Balochistan from physical or mental violence, injuries, neglected or negligent treatment, exploitation or maltreatment, sexual abuse and matters incidental thereto.

\subsection{Minds to Change: Discourse for Awareness}

"The most important thing that parents can teach their children is how to get along without them" (Frank A. Clark). Knowledge is always a powerful deterrent against the uncertainties of life. Young generation is backbone of any society. Their safety is prime concern of all from individual to state level. There are also solutions against this evil of child sexual abuse if matters are observed with socio-economic lens. Social aspect could be more detailed to discuss remedies to secure children from child abuse in Pakistan. At first stage, the role of parents is essential. They should be made aware and trained to address this issue through legal and psychosocial means including asking for help to legal aid and ensuring counselling support for the child. Children must be provided with basic education at early stage to identify acts of sexual abuse and raise voice. As this is a sensitive issue, both parents and siblings feel hesitant to talk about this. Hence, there must be a systematic approach with the following steps:

\section{a) Parents-Child Gap}

Parents must nurture their children in such a way that level of confidence and cooperation will 
be higher between them. Children should not feel absurd while sharing their problems with parents. Whenever they face difficulties, their parents should be their priority to share the issues to bring them out of it.

\section{b) Education about Sexual Abuse}

In Pakistan, social and cultural values are always used as obstacles to talk about sexual abuse by the parents with children. However, children must have proper education about sexual abuse at various age levels. They must have information about their body parts and then further about private body parts. They will give severe reaction if someone makes picture, video or even touches their private body parts. Even if children get engaged in scary or uncomfortable situations, they must know how to call someone for help. Training should be provided in schools and community to make this a social practice.

\section{c) Follow up Policy}

It is not only the duty of parents but community within specific vicinity must have a close observation on the overall activities of their children. This must be conducted in such a way that social life of children may not be spoiled. In this way, children will be safer against wrong doers with social cooperation. Children will also keep them away from social evils.

\section{d) Uncertainties Prevail all the Time}

Public attitude is a dynamic process. There are chances that children can face uncertain situations in their lives. Therefore, they must know how to use different options to get out of these situations. In Pakistan, there are government and non-government organizations for providing help in this matter. Parents should be made aware and provided trained to seek help from these institutions.

\section{e) Formal Education about Sexual Abuse}

There must be formal education about sexual abuse for children through various educational institutions. Seminars, conferences, and lectures should be organised for the public awareness as well to train them how to aware their children. As noticed, by support from government, such activities are being organised on various forums in Pakistan. Still, greater efforts and enough resources are needed to further this process.

\section{f) Reason Based Analysis behind the Crime}

There must be comprehensive analysis of all those reasons, which lead a person to sexual abuse either as a culprit or as a victim. Those factors, either social, economic, or psychological must be focused with diligent attention to bring them on board. No doubt, unemployment, illiteracy, superstition, the business of parents, unrestricted access to social media and internet in Pakistan are reasons behind this evil. However, a calculated and scientific approach can produce a positive social attitude.

\section{g) Morality Based Cultural Values}

Islamic values and culture are based on love for others irrespective of their creed and colour. 
In Pakistan, being an Islamic state, these values are dire need of time. If this culture is promoted, social evils will remain no more. It will make Pakistan a state, where children are safe, and parents are happy. Victim children will also be able to avail a respectable place in society without any psychological issue.

\section{h) Difference between Theory and Practice}

Acts are functional and institutions are operational but still, things are not as better as they should be. Despite funds, commissions, and authorities there is an increase in reported cases of child sexual abuse in Pakistan. It is because there is a gap between the policy and practical work of these institutions. Institutions must perform their functions diligently according to their nature. So that the cases of child sexual abuse may be minimised. There must be the rule of law for all. Culprits must be punished through a transparent process of investigation and trial. To do so, the government of Pakistan is making its utmost efforts for strengthening institutions by providing them funds, restructuring them under the jurisdiction of laws and acts.

\section{Conclusion}

Pakistan as an Islamic state with a clear narrative of "welfare state". However, when talk about human rights, basic needs, morality it lacks them either in one way or in the other. Idea of "State of Medina" reflects all the individuals of this state are responsibility of state with their fundamental rights. State will protect all from those fireballs, which actually spoil our spirit. As denizens of this state, we need not to worry about our lives and lives of our children because we have umbrella of state. Then why things are not getting better? Children are kidnapped, raped, sexually abused and in the end are killed. It is never ever an easy task for parents to collect their bodies from dumps. Children are afraid and parents go to their work with disturbed minds. There are fewer reasons to be happy but many reasons to be sad.

However, all the times, only the state is not responsible for all this. We individuals are also responsible on equal footings. Because it is not understood that duties are also obligatory when we demand for rights. Individuals' role is always first before state's role. People must know that only a cooperative and well-disciplined society can eradicate social evils with collective efforts. It is perhaps easy to lift others' children dead bodies, but it is difficult to pick our own. Every person along with state must play their proper role for the rehabilitation of sexually abused children. They must be treated with respect because if not done so they will think of them as deprived of their rights and a neglected child is always harmful for society. Pakistan will be a prosperous and welfare state only when state, institutions, and individuals will perform their role equally. There will come a time when no child will be sexually abused and there will be no tear sheds.

\section{References}

Bano, M. (Ed.), (2017). Cruel Numbers 2017: A Compilation of statistics on Child sexual abuse cases in Pakistan. Retrieved from SAHIL :http://sahil.org/wpcontent/uploads/2018/04/Cruel-Numbers-Report-2017-1.pdf

Bano, M. (Ed.), (2018). Cruel numbers 2018: A compilation of statistics on child sexual abuse cases in Pakistan. Retrieved from Sahil (Report Highlights): https://sahil.org/cruelnumbers/ 
Corby, Brian. (2006). Child abuse: Towards a knowledge base. Open University Press, Maidenhead, England.

Frank G. B., Morris, L. A. \& MacEachron, A. E. (Oct 1, 1989). Males at risk: The other side of child sexual abuse. SAGE Publications.

Gilbert, N. (1997). Combating child abuse: International perspectives and trends. Oxford University Press

Hill, C. A. (2008). Human sexuality: Personality and social psychological perspectives. Los Angeles: Sage Publications.

Imdad, Z. (April 9, 2019). Over 10 children abused every day in Pakistan in 2018: SAHIL report. Dawn.com. Retrieved from https://www.dawn.com/news/1473645

Khan, M., Khan, N. U. \& Ali, A., (2017). Social impacts of parental imprisonment on left behind children. Liberal Arts and Social Sciences International Journal (LASSIJ), $1(1), 41-48$.

Khan, I. U., Rehman, A. U. \& Muhammad, N. (2017). A sociological analysis of combined jail life of juvenile and adult prisoners. Liberal Arts and Social Sciences International Journal (LASSIJ), 1(1), 1-9.

Khan, I. U., Ullah, S. \& Ali, T., (2018). Child labour migration and access of their parents to basic rights. Liberal Arts and Social Sciences International Journal (LASSIJ), 2(1), 29-36.

Khan, M., Khan, K. \& Khan, I. U. (2017). Economic impacts of parental imprisonment on the left behind children. Liberal Arts and Social Sciences International Journal (LASSIJ), $1(2), 60-68$.

Khushhal, A. Zahid, M. \& Jan, A. (2017). Analysis of familial factors behind children's involvement in delinquent acts. Liberal Arts and Social Sciences International Journal (LASSIJ), 1(2), 50-59.

Maney, A., \& Wells, S. (1988). Professional responsibilities in protecting children: A public health approach to child sexual abuse. Praeger Publishers.

Pakistan Penal Code (Act XLV of 1860)

Rowan, E. L. (2006). Understanding child sexual abuse. University of Mississippi Press.

Smallbone, S., Marshal, W. L. and Wortley, R. (2008). Preventing child sexual abuse: Evidence, policy, and practice. Routledge Publishers.

The Constitution of Islamic Republic of Pakistan. Retrieved from: http://www.na.gov.pk/uploads/documents/1333523681_951.pdf

Wasif, S. (2018, August 31). Child sexual abuse cases surge in 2018. Report Retrieved from: https://tribune.com.pk/story/1791931/1-child-sexual-abuse-cases-surge-2018-report/

National Clearinghouse on Child Abuse and Neglect Information. (2006). What is child maltreatment? Retrieved July 20, 2007 from http://nccanch@ calib.com

Starr, R. H. (1987). Clinical judgment of abuse: Proneness based on parent child interaction. Child Abuse \& Neglect, 11, 87-92

Wolfe, R. (1985). Child abusive parents: An empirical review and analysis. Psychological Bulletin, 97, 462-482.

Gelfand, D., \& Teti, D. M. (1990). The effects of maternal depression on children. Clinical Psychology Review, 10(3), 329-353.

Giovannoni, J. M. (1971). Parental mistreatment: Perpetrators and victims. Journal of Marriage and the Family, 33, 649-657. 